\title{
Changes in heart size after homograft replacement of aortic, mitral, or both aortic and mitral valves
}

\author{
M. Baidya, K. Hollinrake, and Magdi H. Yacoub \\ From the Department of Cardiology and Cardiac Surgery, Harefield Hospital, Harefield, \\ Middlesex
}

Heart size was measured radiographically before and after single or double homograft valve replacement in 69 consecutive patients. Thirty patients had aortic valve replacement, 25 mitral, and 14 both aortic and mitral valve replacement.

For aortic valve replacement a fresh unsupported homograft was inserted in the subcoronary 'position, while for mitral valve replacement a fresh semilunar homograft was inserted into the left atrium. The cardiothoracic index and the maximum transverse diameter of the heart were measured preoperatively and at periods varying from 3 to 19 months postoperatively. All patients who had homograft replacement of the aortic valve showed reduction in heart size compared to 88 per cent (22 out of 25) of patients after mitral valve replacement.

The average reduction in cardiothoracic index was greatest after both aortic and mitral valve (i.e. double valve) replacement (10.7\% of the original value), considerable after aortic valve replacement $(9 \cdot 2 \%$ of the original value), and least after mitral valve replacement $(3.3 \%$ of the original value).

These figures compare favourably with reported changes in heart size after insertion of prosthetic valves.

An attempt is made to explain the different responses of the heart size in three groups studied.

Homografts have been used for aortic valve

- replacement for the last 9 years (Ross, 1962; Barratt-Boyes, 1964) and more recently for - mitral valve replacement (Angell et al., 1969; Yacoub and Kittle, 1969). Compared to prosthetic valves, homografts offer the advantages of central turbulance-free flow characteristics, absence of haemolysis (Yacoub et al., - 1969), freedom from thromboembolic complications (McDonald et al., 1968), and an insignificant gradient across the valve. A change in heart size, as measured on the plain

- thest radiograph, is a useful objective method of evaluating cardiac response to valve replacement. The variable effects of insertion of prosthetic valves on heart size have been reported

(Rastelli, Kincaid, and Kirklin, 1966). The purpose of this paper is to study changes in heart size after homograft replacement of the Aortic, mitral, or both valves, and to attempt to explain the different response in each group.

Received I4 July 1971.

\section{Patients and methods}

Sixty-nine consecutive patients who survived homograft replacement of one or more valves were followed up for a minimum period of three months. All patients had severe lesions of mitral, aortic, or both valves, and were significantly incapacitated. Thirty patients (2I men and 9 women ranging in age between 24 and 62 years) had aortic valve replacement; 25 patients ( 17 men and 8 women ranging in age between 30 and 66 years) had mitral valve replacement, and 14 patients (8 men and 6 women ranging in age between 43 and 59 years) had both aortic and mitral valve replacement. For aortic valve replacement, the valves were inserted in the subcoronary position using two suture lines, a lower interrupted and an upper continuous (Ross and Yacoub, 1969). For mitral valve replacement, a fresh semilunar valve homograft, supported by a Dacron tube, was inserted in the left atrium using autogenous pericardium to refashion a new floor for the left atrium (Yacoub and Kittle, 1969, 1970).

All films were taken in full inspiration at a standard distance of 6 feet in the posteroanterior projection. Each film was examined critically by 
two independent observers, and unsuitable films were excluded. The main reasons for exclusion were as follows.

(1) Incomplete inspiration with a resulting high diaphragm. (2) An indistinct outer border of the heart which could not be accurately delineated. (3) In the largest hearts the lateral border of the cardiac shadow was confluent with the rib cage, and so the cardiac size could not be estimated.

The postoperative films were taken a minimum of 3 months and a maximum of 19 months after operation.

The cardiothoracic index was calculated by measuring the greatest horizontal width of the cardiac shadow and the maximal indirect internal thoracic diameter (Fig. I).

Both the cardiothoracic index and the greatest horizontal width of the heart were taken into consideration in the assessment of results, as they provide a simple and widely used method of evaluating heart size and, more indirectly, of assessing changes in cardiac volume. Keats and Enge (1965) have described a more detailed method of measuring cardiac volumes by simple radiographic techniques, but this method also is not free from error.

In patients with aortic valve replacement the mean interval was Io months and 13 days, in mitral valve replacement 8 months and 22 days, and in double valve replacement 8 months and 25 days.

The values obtained for the cardiothoracic index and the heart size (in $\mathrm{cm}$ ) were analysed statistically by using the Student's $t$ test on the difference between individual pairs of readings taken before and after operation.

\section{Results}

Changes in the cardiothoracic index and individual changes in heart size for the three groups of patients are shown in Fig. 2 and 3, and the mean changes in cardiothoracic index and heart size are represented graphically in Fig. 4 and 5.

All patients who had homograft replace-

FIG. I Method of measuring cardiothoracic index.

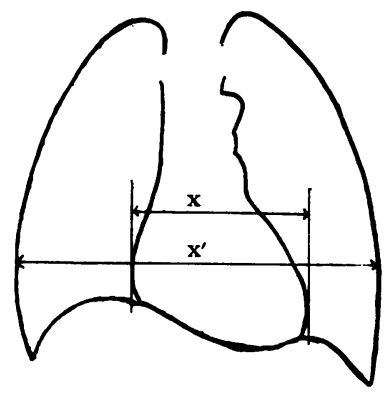

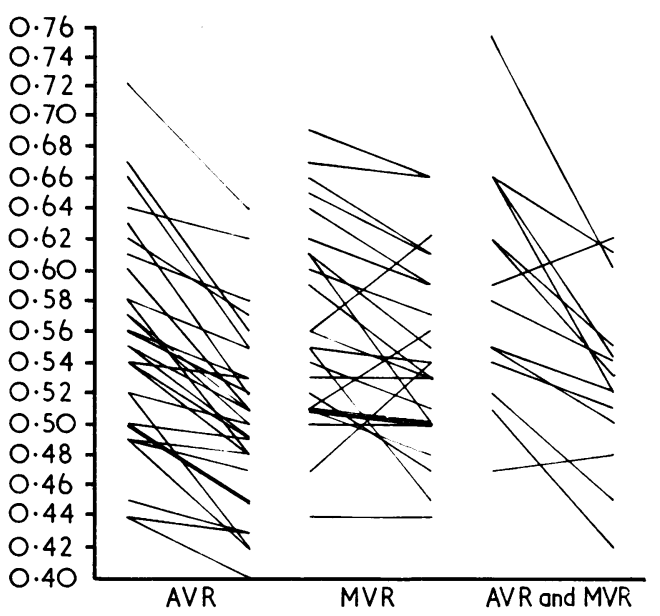

FIG. 2 Changes in cardiothoracic index after homograft replacement of the aortic valve $(A V R)$, mitral valve $(M V R)$, and both aortic and mitral valves ( $A V R$ and $M V R)$.

ment of the aortic valve showed considerable reduction in heart size and in cardiothoracic index, as did all but two patients who had homograft replacement of both aortic and mitral valves. These two patients showed a slight increase in their heart size and cardiothoracic index. This contrasts with patients who had isolated homograft replacement of the mitral valve in whom the reduction in

FIG. 3 Changes in maximal transverse diameter of the heart after homograft replacement of the aortic $(A V R)$, mitral (MVR), or both $(A V R$ and $M V R)$ valves.

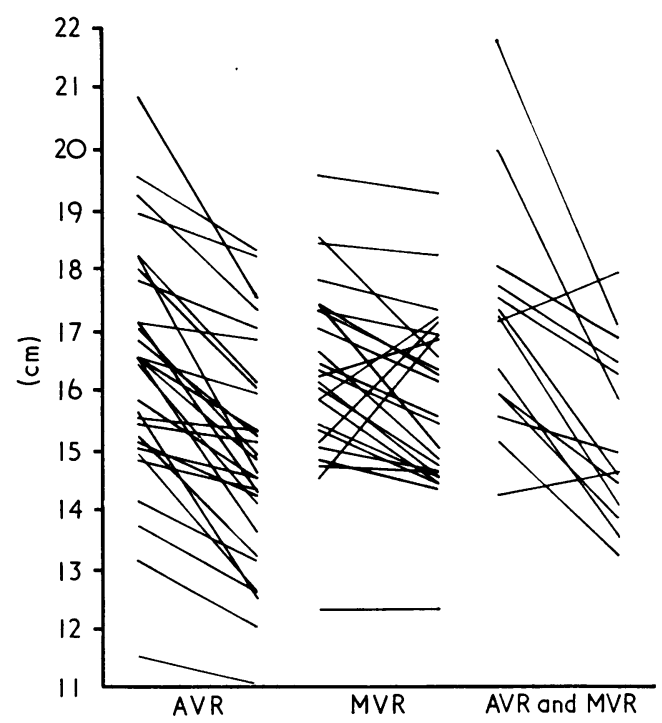




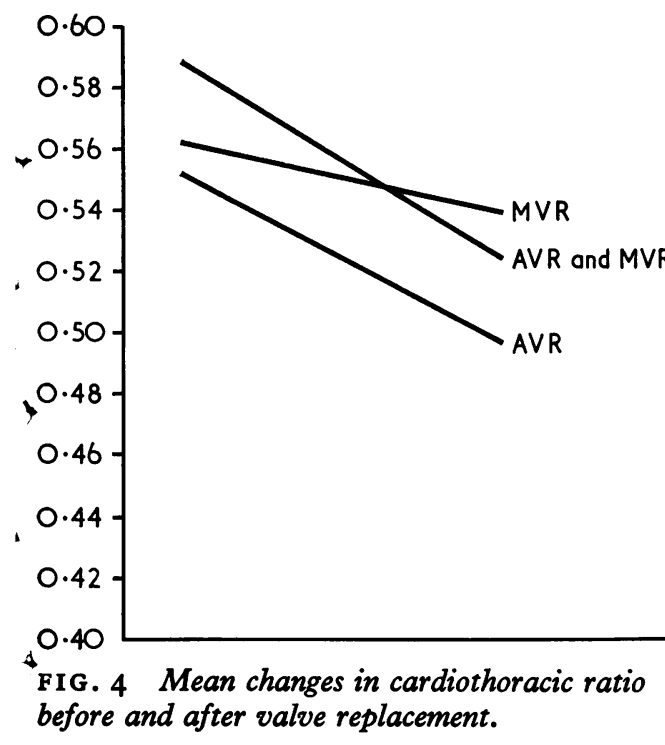

heart size and cardiothoracic index was relatively small. Three patients in this group showed a substantial rise in their heart size and cardiothoracic index (reasons discussed later). A fourth patient showed a minimal increase in heart size, but no change in the calculated cardiothoracic index.

The mean reduction in the cardiothoracic

- index was greatest (Fig. 6) after double valve replacement (from 0.591 to 0.528 ), represent-

-ing a reduction of 10.7 per cent of the original value; considerable (Fig. 7) after aortic valve replacement (from 0.554 to 0.503 ) representing a reduction of $9 \cdot 2$ per cent of the original value. Both these reductions are statistically

FIG. 5 Mean changes in heart size (transverse diameter) after valve replacement.

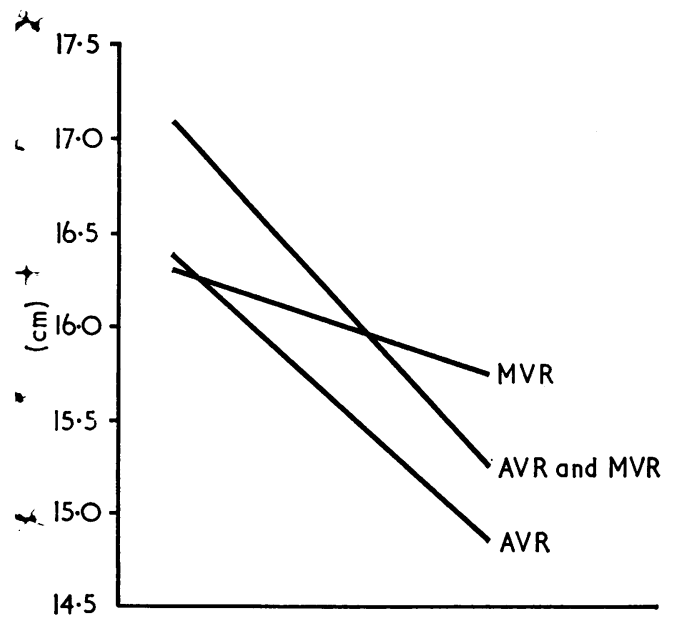

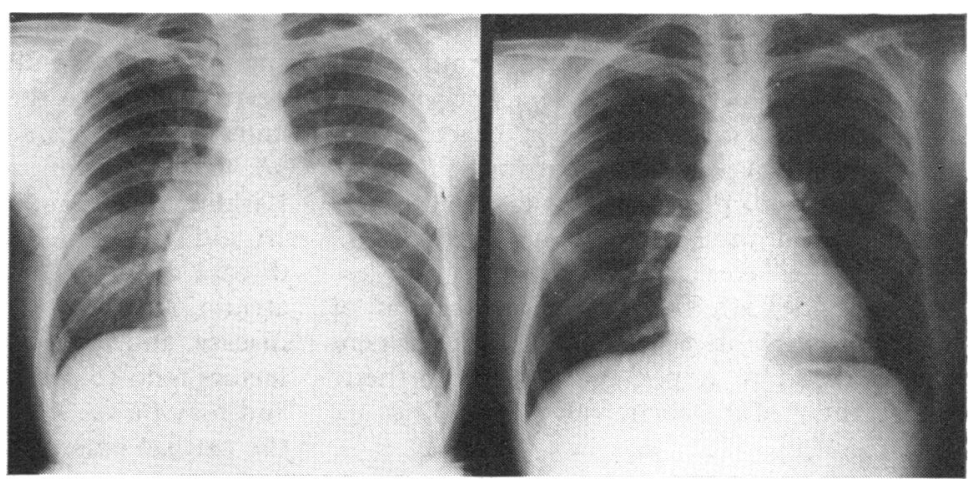

FIG. 6 Chest radiographs before and $3 \frac{1}{2}$ months after aortic and mitral valve replacement.

highly significant $(P<0.001)$. The mean reduction in cardiothoracic index was least after mitral valve replacement (from 0.560 to 0.542 ), representing a decrease of 3.3 per cent of the original value and was significant statistically only at a level of $P<0.02$.

The mean reduction in heart size after double valve replacement was $\mathrm{I} \cdot 88 \mathrm{~cm}$ (from 17.09 to 15.21 ), representing an II per cent reduction of the original value, and $1.53 \mathrm{~cm}$ (from 16.36 to 14.83 ) after aortic valve replacement, representing a reduction of 9.4 per cent of the original value. Both these reductions were highly significant $(P<0.00 I)$. In contrast, the mean reduction in heart size after mitral valve replacement was $0.53 \mathrm{~cm}$ (from 16.28 to 15.75 ), representing a mean reduction of only 3.2 per cent of the original value. This reduction was significant statistically only at a level of $\mathrm{P}<0.02$.

These changes compare favourably to

FIG. 7 Chest radiographs before and 5 months after homograft replacement of the aortic valve.

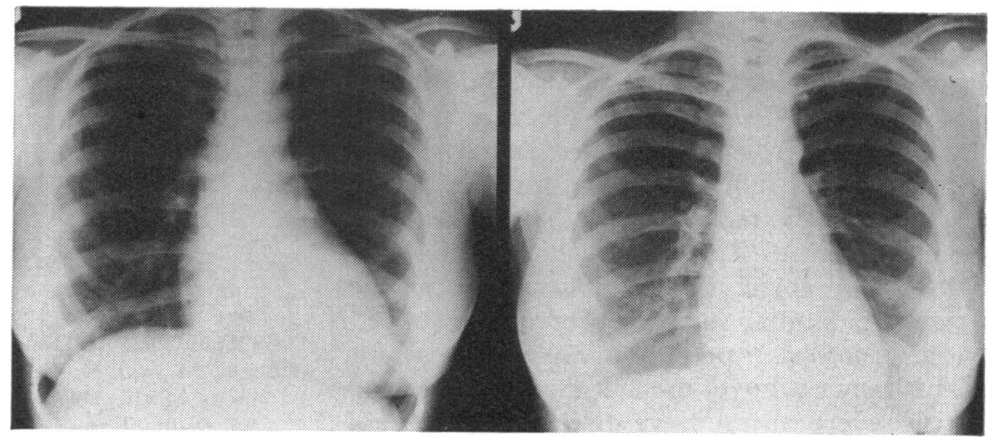


changes in heart size after insertion of a prosthetic valve. All patients who underwent homograft replacement of the aortic valve in our series showed reduction in heart size as compared to 79 per cent of a group of patients who underwent prosthetic replacement of the aortic valve at the Mayo Clinic (Rastelli et al., 1966). The average reduction in cardiothoracic index after homograft replacement of the aortic valve in our series was 9.2 per cent as compared to 9 per cent after prosthetic replacement of the aortic valve (Rastelli et al., 1966).

In our series, 88 per cent of the patients showed reduction in cardiothoracic index after homograft replacement of the mitral valve as compared to 50 per cent of a group of patients who underwent prosthetic replacement of the mitral valve at the Mayo Clinic (Rastelli et al., 1966). The average reduction in cardiothoracic index after homograft replacement of the mitral valve in our series was 3.2 per cent as compared to 2 per cent after prosthetic mitral valve replacement (Rastelli et al., I966).

Patients with aortic and mitral valve disease had the highest cardiothoracic index preoperatively. With two exceptions, all these patients showed decrease in heart size after homograft replacement of the aortic and mitral valve, with a mean reduction in cardiothoracic index of 10.7 per cent

\section{Discussion}

Any reduction in the width of the heart reflects a much greater reduction in its volume. This is illustrated by the fact that a ro per cent reduction in the diameter of a sphere will reduce its volume by approximately 27 per cent. Therefore an average reduction of 9.4 per cent or II per cent after aortic or double valve replacement, respectively, represents a considerable reduction in cardiac volume and, in some cases, may reduce the heart size to within normal limits.

The difference in the response in the heart size after homograft replacement compared to that after prosthetic valve replacement is probably due to the better flow characteristics of a homograft valve and the fact that the rigid intracardiac prosthetic material may interfere with normal cardiac function.

The lesser reduction in heart size after replacement of the mitral valve compared to that after aortic valve replacement, in this series, is similar to that observed by Rastelli et al. (I966) after prosthetic valve replacement. This may be due to the fact that most patients with severe mitral valve disease have impair- ment of myocardial function from previous rheumatic myocarditis or secondary to hypoperfusion due to the low cardiac output state known to occur in these patients (Judson et al., 1964; Austen et al., 1966; Rastelli and Kirklin, 1966; Rouleau, Frye, and Ellis, 1969). In addition, many patients with mitral valve disease have gross enlargement of the left atrium, atrial fibrillation, pulmonary vascular disease, and/or tricuspid valve disease. These factors tend to persist after valve replacement and may be responsible for the persistence of the cardiac enlargement. Over 50 per cent of patients with isolated aortic valve disease in our series were found at operation to have a congenitally abnormal valve (nonrheumatic). These patients usually remain in sinus rhythm and do not have any intrinsic myocardial disease, which explains why they respond with conspicuous reduction in their heart size after valve replacement. In spite of the presence of severe micral disease and the associated adverse factors, it is surprising that the reduction in heart size after homograft replacement of both aortic and mitral valves is much greater than that after isolated mitral valve replacement.

In this series, 9 patients preoperatively had a pulmonary vascular resistance of more than 5 units and 4 of these showed an increase in heart size after replacement of one or more valves. A high pulmonary vascular resistance may therefore be one of the important factors in the persistence of cardiac enlargement postoperatively.

We should like to thank Dr. M. Towers and Dr. W. Somerville for their help in presentation of this paper.

\section{References}

Angell, W. W., Iben, A. B., Gianelly, R., and Shumway, N. E. (1969). Aortic homografts for mitral valve replacement. Circulation, 39, Suppl. I, 39.

Austen, W. G., Corning, H. B., Moran, J. M., Saunders, C. A., and Scannell, J. G. (1966). Cardiac haemodynamics immediately following mitral valve surgery. Fournal of Thoracic and Cardiovascular Surgery, 51, 468.

Barratt-Boyes, B. G. (1964). Homograft aortic valve replacement in aortic incompetence and stenosis. Thorax, 19, 131.

Judson, W. E., Ardiaz, J., Strach, T. B. J., and Jennings, R. S. (1964). Postoperative evaluation of prosthetic replacement of aortic and mitral valves. Circulation, 29, Suppl., 14 .

Keats, T. E., and Enge, I. P. (1965). Cardiac mensuration by the cardiac volume method. Radiology, 85, 850.

McDonald, A., McDonald, L., Resnekov, L., Robinson, M., and Ross, D. (I968). Homograft replacement of the aortic valve. Immediate results and follow-up. Lancet, 2, 469. 
Rastelli, G. C., Kincaid, O. W., and Kirklin, J. W. (1966). Heart size after isolated replacement of mitral or aortic valve. Proceedings of the Staff Meetings of the Mayo Clinic, 41, 217.

Rastelli, G. C., and Kirklin, J. W. (I966). Haemodynamic state early after prosthetic replacement of mitral valve. Circulation, 34, 448.

Ross, D. N. (1962). Homograft replacement of the aortic valve. Lancet, 2,487 .

Ross, D. N., and Yacoub, M. H. (1969). Homograft replacement of the aortic valve. A critical review. Progress in Cardiovascular Diseases, II, 275.

Rouleau, C. A., Frye, R. L., and Ellis, F. H. (1969). Haemodynamic state after open mitral valve replacement and reconstruction. Fournal of Thoracic and Cardiovascular Surgery, 58, 870.
Yacoub, M. H., and Kittle, C. F. (1969). A new technique for replacement of the mitral valve by a semilunar valve homograft. Fournal of Thoracic and Cardiovascular Surgery, 58, 859.

Yacoub, M. H., and Kittle, C. F. (1970). Sterilization of valve homografts by antibiotic solutions. Circulation, 41, Suppl. II, 29.

Yacoub, M. H., Kothari, M., Keeling, D., Patterson, M., and Ross, D. N. (1969). Red cell survival after homograft replacement of the aortic valve. Thorax, 24, 283.

Requests for reprints to Magdi H. Yacoub, F.R.C.S., Thoracic and Cardiac Surgical Unit, Harefield Hospital, Harefield, Middlesex. 